\title{
Recommendations for Social Media Activities to Positively Influence the Economic Factors
}

\author{
Yash CHAWLA, Grzegorz CHODAK \\ Wroclaw University of Science and Technology, Wroclaw, Poland \\ \{yash.chawla, grzegorz.ghodak\}@pwr.edu.pl
}

\begin{abstract}
Social Media has become an important part of people life today, all over the world. The number of social media users has grown rapidly during last decade and are projected to keep growing. In this article the statistics concerning social media usage and the global characteristics of this phenomenon were presented. According to researchers, the number of social media users will exceed 3.02 Billion by 2019. Such a huge number of active users, have a strong influence on various economic areas. Social media has changed, the way companies carry out marketing and branding activities, the flow of information or news in the global scenario, international trade, public awareness, transparency of government or public administration, employability or talent acquisition etc. These socio-economic or micro-economic factors inevitably influence the economic factors of each country. In this article, the different aspects of growing number of social media users were analysed. Also, we recommend a set of guidelines for individuals, businesses and government which would positively impact the efficiency of social media usage. These recommendations, brings about a balance between the social, personal and professional aspects of individuals. For businesses and governments, they yield a better connectivity with the citizens / customers. A combination of both these outputs results in positive influence on economic factors.
\end{abstract}

Keywords: Social Media, Facebook, Macroeconomics, Economic Growth

\section{$1 \quad$ Introduction}

The increasing popularity of social media during last decade is one of the most interesting phenomenon of XXI century. Over 2 billion Facebook users and hundreds of millions of users in other social media services [11] have a direct or indirect influence, on various aspects of life [1,22], and also the Economy. People who spend time on social media engage in relationships, watch advertisements, recommend products / brands, and indulge in lot of other things that affect the economy at both microeconomic and macroeconomic levels [5, 15, 24].

In the literature there were only a few papers which analyzed the impact of social media on economy from macroeconomic perspective $[5,17]$. In our paper we want to fill this gap in the literature and make basis for further research in this area. 
The main purpose of this article is to recommend important points that should be applied by social media users, i.e individuals, businesses / firms \& government, for positively influencing the economic factors. The growth of internet through mobile devices and the vast usage of social networking sites by users around the world have direct or indirect effect on various economic factors. The recommendations for activities stated in this article can positively influence these economic factors, resulting in GDP growth of the country.

The structure of the article is as follows. In the first section, current statistics concerning Internet and social media usage are shown. There-after the mutual relations between social media and economy are analysed. In the section after that, recommendations, for effective usage of social media, are enlisted for individuals, businesses and government. The last section includes short conclusions.

\section{The current scenario of Internet \& social media}

\subsection{Internet usage}

Internet usage has increased significantly during last decade and mobile internet services were one of the key factors which contribute to this growth [1]. Mobile data traffic increased by 4000 times from 2005 to 2015 . If we consider the period between 2000 to 2015, then the increase in mobile data traffic is a staggering 400 million times. This has been possible because of the increased affordability and availability of smart phones as well as the development in mobile communication technology over the last decade. Internet usage on smartphone is estimated as $97 \%$ of the total mobile data traffic. According to the usage patterns, a prediction by CISCO puts the monthly global mobile data traffic at 30.6 exabytes and number of mobiles connected per capita at 1.5 . Three fourth of the mobile data traffic would be videos by 2020 . Further, with the implementation of $4 \mathrm{G}$, the average global mobile speed will surpass $3 \mathrm{Mbps}$ by 2017. At that point the monthly mobile data traffic is estimated at around 9.9 exabytes. These predictions illustrates that there will be an increase of over $300 \%$ in the next three years [6].

\subsection{Development and Growth of Social Media}

In 1979, Tom Truscott and Jim Elis from Duke University created the Usenet, which was a system that enabled the users to have a discussion by posting public messages over the internet. This was one of the first signs of digital social networking. In 1997 an early social networking site named "Open Diary" was founded by Bruce and Susan Abelson. It was around the same time, the word "weblog" was first used. This formed the bases of the word "blog" a year later, as one of the bloggers jokingly divided the word in a phrase "we blog". With the further evolution of internet speeds and affordability, social networking sites like MySpace and Facebook were founded. "Social Media" became a popular term henceforth [1]. Currently, majority of the time spent on the internet is on social media, which includes blogs, virtual games, social 
worlds, social networking sites, collaborative projects, building communities etc. [1, 22]. Future evolution of the world wide web is going to be connected with social media, affecting every individual and business directly or indirectly, as the user base of social media expands rapidly $[2,25]$.

According to a study carried out at the Pew Research Centre in America, over 65\% of the American adults were using social media in 2015 as compared to $7 \%$ in 2005. Although young adults aging between 18 to 29 years are in majority, the growth of social media users was observed in all the age groups. Based on gender, in 2015, it was found that there was a modest gap of $2 \%$ between men \& women, with women leading the way. As far as the classification of the users based on socio-economic factors are concerned, it was observed that individuals with higher education level and household income, used social media more. Nevertheless, since past few years it was noted that over $50 \%$ of the users from lower income houses or less education had initiated using social media actively. In terms of users by geographic location: rural, suburban and urban; it was observed that the patterns were consistent over the decade of study with the percentage of users standing at 58, $68 \& 64$ respectively [23].

Analysing the global social media users base, a survey by eMarketer published in July 2017 shows a steady rise in the number of users worldwide. (Fig. 1).

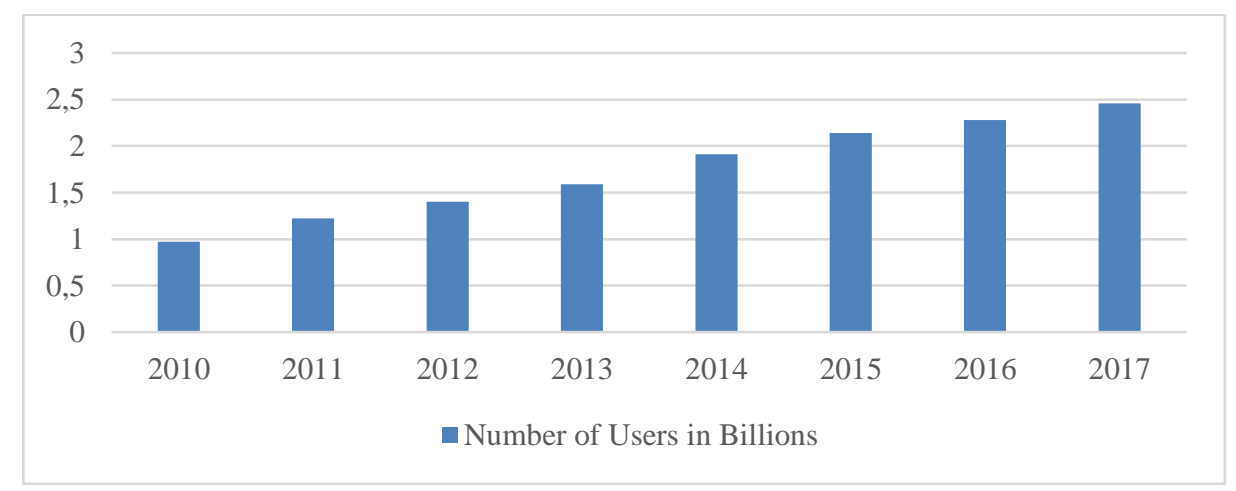

Fig. 1. Year wise number of social media users globally on all platforms [16]

According to Eurostats, considering all the 28 countries in the European union, the frequency of Social Media usage by residents can be divided into everyday users (26.2\%), every week users (13.3\%), once a month users (2.8\%), several times a month users $(5.2 \%)$, not in the last twelve months $(50.5 \%)$ and at least once a year $(1.9 \%)$. These figures are very recent as they were updated on 19th September 2017. Country wise distribution of the users in European Union, on the same basis as above, is presented in the Figure 2. It can be seen that the highest percentage value of every day users exists in Norway (45.5\%), followed by Malta (42.6\%) \& Ireland (41.8) [7]. 


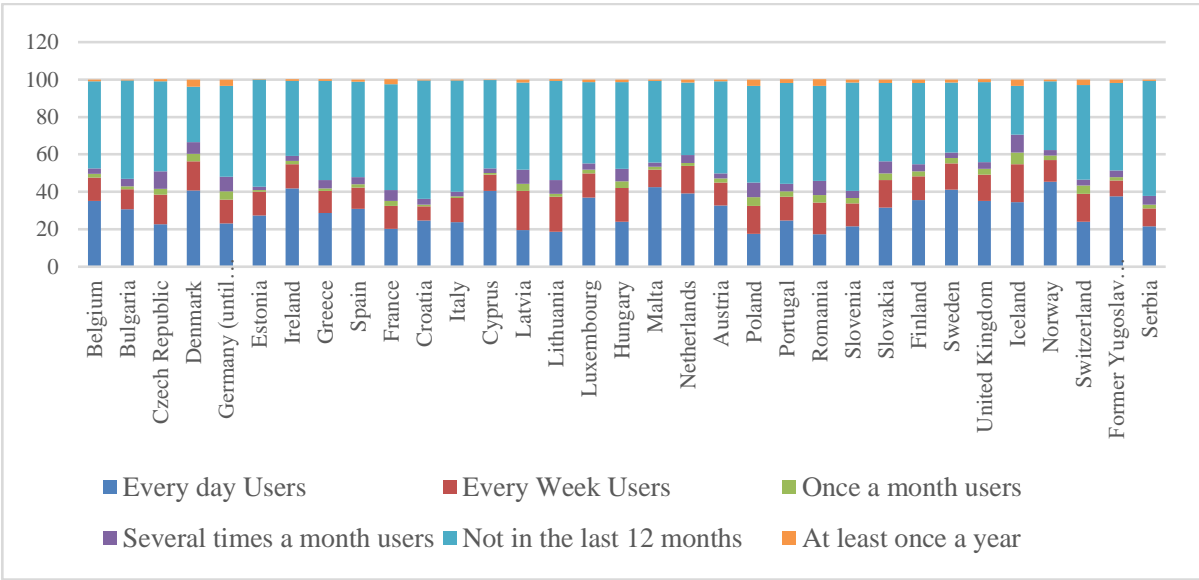

Fig. 2. Demographics of European social media usage on basis of time spent [7]

The projections for usage of social media in the coming years, show a steady rise in the number of users. In 2018, the user base is projected to grow by another 0.16 billion and reach to 2.62 billion social media users. This number would further grow to 2.77 billion, 2.9 billion and 3.02 billion in 2019,2020 and 2021 respectively [16].

\subsection{The spectrum of social media and the current user base}

Users are active on more than one social media site, having the variety of different possibilities. Largest social networking website is decisively Facebook. A report by Kepios in September 2017 shows the statistics of the top 20 social networking websites in the world (Fig. 3). As it can be seen there are four social networking website with the number of users over 1 billion and next four with the number of users over 0.5 billion [11]. 


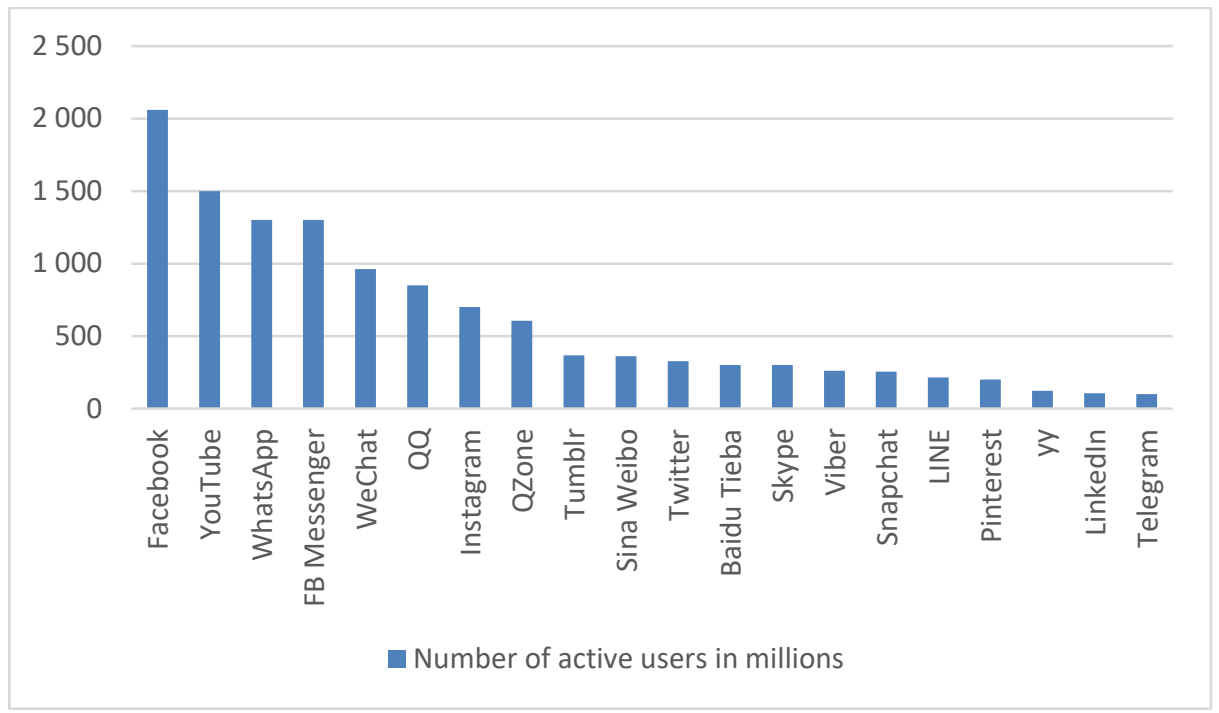

Fig. 3. User base of top 20 social networking websites in 2017 [11]

\section{Social media \& Economy}

The way of disseminating information as well as the way in which individuals or society perceives the information, both can affect the macroeconomic factors. SuHeng et al. (2013) [5] as well as Jana Nunvářová and Pavel Bachmann (2017) [17] have extensively proved the same in their work on Social Networks \& Macroeconomic Stability. In their work they describe three components of the economy which are also used for the calculation of Gross Domestic Product (GDP) by the expenditure approach. Consumption - the expenditures by individuals or households, Investment - the expenditure by the firms / businesses and Government spending, being the three components. Individuals these days prefer to read news on social media and also it has also become their prime source for personal updates. Optimizing the use of social media by individuals, businesses / firms and government in an effective way, would bring about a positive impact on economic growth $[5,17]$.

Factors of the economy, such as the employability of the citizens, are directly affected by the rising of social media. In this information age, the students need to be equipped with the most accurate knowledge about their fields as well as be connected to the right people globally. Managing one's career as well as getting proper direction at proper time by professionals is also an area which is aided by professional social networking sites dedicated to the labour market, like LinkedIn. Social media provides a very effective platform supporting the flow of information on the labor market. This allows more effective entry into the labour market for students and a higher mobility on the labour market for employees for both young as well as experienced professionals. Social media may also decrease the cost of recruiting workers for 
businesses. Vladlena Benson et al. (2013) have highlighted this impact in their work on Social Career Management [3].

Social media also has an impact on the trade, especially e-commerce, because SM marketing allows very accurate targeting of advertising audience at lower cost. This increases the effectiveness of marketing efforts by the businesses [9]. Several companies use Facebook, Instagram and other social networking platforms to their specific group of customers. Also, small niche businesses use social media services (e.g. Facebook, YouTube) to spread wide scale awareness about their products, what was previously difficult to carry out in such scale. These microeconomic activities, influence the aggregated supply and demand.

Effective use of social media by businesses enables building relationships with customers and increases brand awareness [8]. Today's consumers look for product details in the internet and discuss about them using social media before making the actual buying decision. [18]. Sharing the information about products in Internet connected with social influence may cause Bandwagon effect or even speculative bubble.

Sustainable business is a very important part of a stable economy. It contributes to the overall development of economy as well as generate employment, which takes the macroeconomic factors towards stability. Cristian Bogdan Onete, et al. (2013) in their work on social media in sustainable business development, highlighted that social media can be a good supporting tool for development of goods \& services that can become sustainable [4]. For businesses it is really important to be connected to the customers and social media gives them a very convenient medium to do so [24]. Seonjeong Lee (2016) published his article about the same research area, but for the hotel industry. In his study he had found that the social media activities of the businesses' that influenced customer's psychological needs and impact on a sense of well-being, proved to be really positive for the brand usage intent of the customers. In the study it was also found that involving the customers in content creation and encouraging or rewarding them for sharing their experiences through social networking sites, attracted customers to engage more with the brand [12].

It is also worth mentioning that excessive \& ineffective usage of social media proves to harmful not just socially or psychologically but also physically. The negative effects of social media abuse, such as the possible health problems with the cervical spine (this is due to the excessive use of smartphones and the unnatural position of the bent neck), social alienation, mental problems social media addition etc. All these problems result in the increase of health care expenses.

\section{$4 \quad$ Recommendation for effective use of social media}

It is almost impossible to ask social media users, especially the youth, to decrease the time they spend on social media. This is because social media has got integrate in their lifestyles. Hence, increasing the effectivity or positive outcome of this time spent on social media, would be one of the best case scenarios. The recommendations below, for social media users, can improve the efficiency of its use as well as it 
effectiveness. The suggestions are divided into three groups: for individuals, for businesses/firms and for government.

\subsection{For individual users}

In this section we propose set of suggestions which can improve the efficiency of social media usage by individuals. First of all individual users need to be really vigilant in differentiating the fake news from the truth. This can be done by verifying the source of information back to its origin. If the time / effort doesn't permit verification, then further circulation of information or news by the individual should be avoided. Social media news feed algorithms are becoming smarter by the day and show only the most relevant posts made by various users to individuals based on their activities. Following the right path as suggested above would aid the algorithms also to identify the fake news patterns. Moreover, individuals need to build up a strong social media profile, right from the time they enter into college [1, 3, 20, 22].

Individuals need to have a very clear vision of who they are, who they want to be and define their goals in life, before proceeding towards projecting themselves. Once this is decided, individuals need to ensure that the content they are sharing is in line with their defined goals \& objectives. This is one of the most important factors which is missing from the social media activities of users today. Asking questions is always good, hence before posting, individuals needs to always ask himself / herself, that the content they are sharing would be beneficial to them or to their friends / family members / colleagues or in general to anyone who views it. If yes, then how? If no, then the content shouldn't be shared. Our lives are a combination of three roles, Personal, Professional \& Social. Therefore, it is very important to have a fine balance between all the three roles through the activities on social media. While interacting with content posted by others, the goals / objects set by an individual should be adhered to. One should interact with only those posts / content which are in line with their objectives. Entertainment or amusing content, shouldn't cause a deviation from the same. It is very important to train the social media profiles, to show the most relevant information that is useful to the user. This can be achieved by keeping the activities aligned as suggested above. One needs to be really clear and understandable with their comments, their suggestion or any other content they share on social media. A share has the highest impact (always put views on the post shared from others, avoid sharing without your own views in the caption), then comes the comment and then a like or a reaction. A general observation while using social media is the annoying tags that we get on photos totally irrelevant to us. Never tag people, if the post is not relevant for them. Repeated tagging of people in un-relevant content for the purpose of increasing the reach, actually increases the spam score and decreases the reach of the posts gradually. Being punctual, regular, consistent and precise with sharing content goes a long way in creating a better impact on the audience. 


\subsection{For businesses / firms}

Businesses and firms have been taking up social media marketing to great effect for over half a decade now. Since past couple of years, the integration of social media in the customer relationship management has also evolved to a great deal. Today the terms such as re-marketing, influencer marketing, highly precise targeting marketing etc. have become popular among businesses due to the high number of users being active in social media [13, 18, 21].

Now the businesses need to take the use of social media further by using it to influence positive change, for training \& development of internal human resources, utilizing the internal resources as influencers, stress more on organic \& content rich marketing, building up personal repot with customers etc. A few top end companies have already initiated doing this. But, the majority of the users of social media are in the developing countries. This makes it important for the businesses in those regions as well as businesses targeting those regions to be effective in reaching out there. Some of the companies which are trying to connect with consumers through social media are: Oreo - introducing engaging content, Netflix - making an effort to understanding their audience, Pampers - reaching its specific target market, Dove creating inspiring content, GoPro - engaging customers in content creation, Royal Dutch Airlines - addressing customer grievances, Always - engaging users for social change etc.

\subsection{For Government}

Social media has had a lot of impact on the political outcomes in the recent times. Government policy plays a very important role in sustaining the stability of macroeconomic factors in the each country. Maintaining \& balancing the cash flow, managing the policies of imports \& exports, supporting local businesses etc. all influence the macroeconomic factors. Here the role of social media for the government is vital $[10,13,15]$.

Social media trends affect the economic factors such as the stock market [14], consumer behavior in expenditures and many other factors. It is very important for the governments to have social media integrated into public governance. Literacy about social media is still not considered as important subject in the education system at lower levels. Integration of social media knowledge in the high school curriculum is of utmost importance, if a country wants to have socially literate $\&$ responsible citizen in the times to come. Currently social media journalism /citizen journalism doesn't require a license, which has boosted the growth of fake news markets. Proper licensing for such e-portals should be made mandatory and initiator of fake news content should be punished by law. Fighting corruption is one of the major concerns for governments of developing countries. Social media is a very powerful tool for the same [10]. Citizen journalism through social media in a monitored way would prove to be really impactful in the fight against corruption. Government should also monitor the flow of forex out of the country due to the marketing expenditure carried out by the business on search engines as well as social media. 


\section{$5 \quad$ Projected outcomes of the above recommendations}

The above recommendation would bring out an integration of individuals for a better society, integration of society, businesses \& government for a better economy. For individuals the recommendations listed would improve their social \& professional presence. This would give them better career opportunities as well social integration. Personal life is an aggregate of the social \& professional life, hence it would be positive for all the three aspects of an individual's life. As the users become more alert as well as aware, they would make better social, professional, political and commercial decisions. The business would adapt more organic methods of promoting their business, involving more and more citizen in the same. Currently, the largest social media sites as well as search engines are based in the United States. Hence for rest of the countries, when business spending for marketing on these sites, basically forex flow out of the country into the United States. Increase in more organic marketing would decrease this flow of forex out of the country. For governments, the capability of reaching out to majority of the citizens as well as businesses through social media would decrease the gap between them. Hence a better informed government and a more sustainable government system would evolve. As the three important components of an economy, i.e. individuals, businesses \& government, are becoming more effective through these recommended social media activities, therefore the Economy is bound to be influenced positively.

\section{Conclusions}

Growth of social media is projected to hit new heights in the next four years. Another billion people are projected to become active on social media, apart from over 2 billion people who are already frequent users of it. These large numbers, make the effective use of social media - a necessity. Individuals need to equip themselves, to have the power to differentiate the right from the wrong. They also need to pave their social, personal and professional lives, to get the maximum desired output, which is aided by social media. Moreover, the businesses as well as governments have to use social media effectively in-order to keep the macro-economic factors stable, taking the country towards growth. In the article, due to the limited volume we pointed out only selected aspects of influence of social media on economy, and we gave brief recommendation on how to use it in more effective way. The directions of further research that we intend to undertake include elaborate description of the macroeconomic indicators that social media influence the most.

\section{References}

1. Kaplan, A.M., HaenleinM.: Users of the world, unite! The challenges and opportunities of Social Media, In Business Horizons, vol. 53, Issue 1, 2010, pp. 59-68, ISSN 0007-6813, DOI: 10.1016/j.bushor.2009.09.003. 
2. Asur, S., Huberman, B. A.: Predicting the Future with Social Media, 2010 IEEE/WIC/ACM International Conference on Web Intelligence and Intelligent Agent Technology, Toronto, ON, 2010, Pages 492-499. DOI: 10.1109/WI-IAT.2010.63.

3. Benson, V., Morgan, S.e, Filippaios, F.: Social career management: Social media and employability skills gap, In Computers in Human Behavior, vol. 30, 2014, pp. 519-525, ISSN 0747-5632, https://doi.org/10.1016/j.chb.2013.06.015.

4. Bogdan Cristian Onete, Dina Răzvan, Vlad Denisa Elena, Social media in the development of sustainable business, Amfiteatru Economic, vol. XV, Special No. 7, November 2013, pp, 659-670, ISSN: 1582-9146 (Print); 2247-9104 (Online).

5. Chen Shu-Heng, Chang Chia-Ling, Wen Ming-Chang.: Social Networks and Macroeconomic Stability. Economics: The Open-Access, Open-Assessment E-Journal, 8 (2014-16): 1-40. DOI: 10.5018/economics-ejournal.ja.2014-16

6. Cisco Visual Networking Index: Global Mobile Data Traffic Forecast Update, 2015-2020 https://www.cisco.com/c/dam/m/en_in/innovation/enterprise/assets/mobile-white-paperc11-520862.pdf , Last accessed: 2017/10/26

7. Frequency of communication via social media by sex, age and educational attainment level , Eurostat Report of Social Media Usage 2015, updated 2017, http://appsso.eurostat.ec.europa.eu/nui/show.do?dataset=ilc_scp13\&lang=en, Last accessed: 2017/10/27

8. Hudson, S., Li Huang, Roth, M. S., Madden, T. J.: The influence of social media interactions on consumer-brand relationships: A three-country study of brand perceptions and marketing behaviors, In International Journal of Research in Marketing, vol. 33, Issue 1, 2016, pp. 27-41, ISSN 0167-8116, DOI: 10.1016/j.ijresmar.2015.06.004.

9. Ioanid, A., Militaru, G., Negoita, O. D., Dumitriu, D.: Managing business using social networks: The relation between a company's social media activities and the results obtained. Bucharest, Issue 7, Oct 2015, pp. 211-219. Niculescu Publishing House.

10. Ionescu, L.:, E-Government \& social media as effective tools in controlling corruption in public administration. Economics, Management \& Financial Markets, vol. 11, Issue 1, pp. 66-72.

11. Kepios: Global social networks ranked by number of users 2017, Digital in APAC 2017, https://www.statista.com/statistics/272014/global-social-networks-ranked-by-number-ofusers/, Last accessed on: 2017/10/27

12. Lee, S.: The Effect of Social Networking Sites' Activities on Customers' Well-Being, Journal of Hospitality \& Tourism Research, 201X, Vol. XX, No. X, Month 2016, Pages 120, DOI: $10.1177 / 1096348016675926$.

13. Li Qing, Wang TieJun, Li Ping, Liu Ling, Gong Qixu, Chen Yuanzhu: The effect of news and public mood on stock movements, In Information Sciences, vol. 278, 2014, pp. 826840, ISSN 0020-0255, DOI: 10.1016/j.ins.2014.03.096.

14. Lin Shen, Ren Da, Zhang Wei, Zang Yongjie, Shen Dehu: Network interdependency between social media and stock trading activities: Evidence from China, In Physica A: Statistical Mechanics and its Applications, vol. 451, 2016, pp. 305-312, ISSN 0378-4371, DOI: 10.1016/j.physa.2016.01.095.

15. Liu Ling, Wu Jing, Li Ping, Li Qing: A social-media-based approach to predicting stock comovement, In Expert Systems with Applications, vol. 42, Issue 8, 2015, pp. 3893-3901, ISSN 0957-4174, DOI: 10.1016/j.eswa.2014.12.049.

16. Number of social network users worldwide from 2010 to 2021 (in billions) - eMarketer, http://www.statista.com/statistics/278414/number-of-worldwide-social-network-users/, Last accessed: 2017/10/29 
17. Nunvářová, J., Bachmann, P.: The influence of social networks on macroeconomic stability. In: Pavel Jedlička, Petra Marešová, Ivan Soukal, International scientific conference Hradec Economic Days 2017, Hradec Králové, Czech Republic, pp 636-642. ISSN 2464-6059 (Print), ISSN 2464-6067 (Online), ISBN 978-80-7435-664-3, University of Hradec Králové, Czech Republic (2017)

18. Parzonko, A.: Wpływ mediów społecznościowych na zachowania konsumentów. Handel Wewnętrzny, (6 (359)), 122-131. (2015).

19. Relling, M., Schnittka, O., Sattler, H., Johnen, M.” Each can help or hurt: Negative and positive word of mouth in social network brand communities, In International Journal of Research in Marketing, vol. 33, Issue 1, 2016, pp. 42-58, ISSN 0167-8116, DOI: 10.1016/j.ijresmar.2015.11.001.

20. Rosso, A.: Integrating your social media activities. Collector, 80(5), 22-27. Retrieved from https://search.proquest.com/docview/1651962021 ?accountid=46407(2014).

21. Saboo Alok R., Kumar V., Ramani Girish: Evaluating the impact of social media activities on human brand sales, In International Journal of Research in Marketing, vol. 33, Issue 3, 2016, pp. 524-541, ISSN 0167-8116, DOxI: 10.1016/j.ijresmar.2015.02.007.

22. Scott Carol F., Bay-Cheng Laina Y., Prince Mark A., Nochajski Thomas H., Collins R. Lorraine: Time spent online: Latent profile analyses of emerging adults' social media use, In Computers in Human Behavior, vol. 75, 2017, pp. 311-319, ISSN 0747-5632, DOI: 10.1016/j.chb.2017.05.026.

23. "Social Networking Usage: 2005-2015." Pew Research Center. October 2015. http://www.pewinternet.org/2015/10/08/social-networking-usage-2005-2015/, Last accessed: 2017/10/26

24. Stephen Andrew T., Lehmann Donald R.: How word-of-mouth transmission encouragement affects consumers' transmission decisions, receiver selection, and diffusion speed, In International Journal of Research in Marketing, vol. 33, Issue 4, 2016, pp. 755766, ISSN 0167-8116, DOI: 10.1016/j.ijresmar.2016.08.003.

25. Zhang Xiaohang, Wang Cenyue, Li Zhengren, Zhu Ji, Shi Wenhua, Wang Qi: Exploring the sequential usage patterns of mobile Internet services based on Markov models, In Electronic Commerce Research and Applications, vol. 17, 2016, pp. 1-11, ISSN 15674223, DOI: 10.1016/j.elerap.2016.02.002. 